\title{
A Demographic Analysis on Prerequisite Preparation in an Advanced Data Structures Course
}

\author{
Sophia Krause-Levy \\ University of California San Diego \\ skrausel@eng.ucsd.edu \\ Leo Porter \\ University of California San Diego \\ leporter@eng.ucsd.edu
}

\author{
Sander Valstar \\ University of California San Diego \\ svalstar@eng.ucsd.edu \\ William G. Griswold \\ University of California San Diego \\ wgg@eng.ucsd.edu
}

\begin{abstract}
Previous work in computing has shown that Black, Latinx, Native American and Pacific islanders (BLNPI), women, first-generation, and transfer students tend to have worse outcomes during their time in university compared to their majority counterparts. Previous work has also found that students' incoming prerequisite course proficiency is positively correlated with their outcomes in a course. In this work, we investigate the role that prerequisite course proficiency has on outcomes between these groups of students.

Specifically, we examine incoming prerequisite course proficiency in an Advanced Data Structures course. When comparing incoming prerequisite course proficiency between demographic pairs, we only see small differences for gender or by first-generation status. There is a sizeable difference by BLNPI status, although this difference is not statistically significant, possibly due to the small number of BLNPI students. In addition, we find that transfer students have sizeable and statistically significantly lower prerequisite course proficiency when compared to non-transfer students. For BLNPI and transfer students, we find that they also have lower grades in the prerequisite courses, which may partially explain their lower prerequisite course proficiency. These findings suggest that institutions need to find ways to better serve BLNPI and transfer students.
\end{abstract}

\section{CCS CONCEPTS}

\section{- Social and professional topics $\rightarrow$ Computing Education.}

\section{KEYWORDS}

prerequisites, curriculum, knowledge retention, computing education, underrepresentation, diversity

\section{ACM Reference Format:}

Sophia Krause-Levy, Sander Valstar, Leo Porter, and William G. Griswold. 2022. A Demographic Analysis on Prerequisite Preparation in an Advanced Data Structures Course. In Proceedings of the 53rd ACM Technical Symposium on Computer Science Education V. 1 (SIGCSE 2022), March 3-5, 2022, Providence, RI, USA. ACM, New York, NY, USA, 7 pages. https://doi.org/10. $1145 / 3478431.3499337$

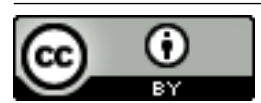

This work is licensed under a Creative Commons Attribution International 4.0 License.

SIGCSE 2022, March 3-5, 2022, Providence, RI, USA

(C) 2022 Copyright held by the owner/author(s).

ACM ISBN 978-1-4503-9070-5/22/03.

https://doi.org/10.1145/3478431.3499337

\section{INTRODUCTION}

Black, Latinx, Native American and Pacific Islander (BLNPI) students and women are traditionally underrepresented in computing compared to their majority counterparts who are White and Asian men [35]. In computing, women and BLNPI students are retained at a lower rate than their majority counterparts [34] and tend to have worse outcomes during their time studying computing $[3,21,22,27]$. Previous work in computing education has identified various factors that may impact students from groups that are typically underrepresented in computing, such as early exposure to computing $[3,15,16,30]$, impostor phenomenon [20], sense of belonging [13] and prerequisite knowledge [27]. With the knowledge that these the various factors are affecting these populations of students, the question becomes: to what degree are these factors affecting student outcomes? Answering this question may identify possible interventions to help these students. In this paper we focus on understanding the role prerequisite course proficiency may play in the disparities between demographic groups.

Recent work by our research group has shown that students do not have the level of prerequisite course proficiency coming into a course that instructors expect $[14,26]$. We define a prerequisite course as a formally required course that students must take before enrolling in a subsequent course that usually imparts skills or knowledge that the subsequent course expects students to have mastered. We define and measure prerequisite course proficiency as the degree to which students have mastered the concepts and skills taught in prerequisite courses. Students have a wide range of prerequisite course proficiency on entry to a course, and concerningly are less prepared than expected [14, 26]. Prerequisite grades are also correlated with prerequisite course proficiency [14].

Motivated by current events and these recent results, we wanted to better understand the degree to which it plays a role in the disparity of outcomes between groups typically underrepresented in computing and their majority counterparts. In this paper we look at the relationship between prerequisite course proficiency for the different demographic groups of gender, BLNPI status, firstgeneration (FG) status ${ }^{1}$ and transfer status ${ }^{2}$ in an Advanced Data Structures (ADS) course through the use of a pre-term test used to

\footnotetext{
${ }^{1}$ First-generation students are students who are members of the first-generation in their family to attend college.

${ }^{2}$ In our country, it is common for a portion of students to enter university after completing a 2-year college program that fulfills General Education requirements and, typically, a couple computing courses. We refer to these students as "transfer" students. Typically, transfer students are more socioeconomically diverse than those students entering university directly.
} 
measure students' incoming prerequisite course proficiency and students' prerequisite course grades. Our results are as follows:

- Women and first-generation students do not seem to start ADS with less prerequisite course proficiency. We did not find anything to suggest that women or first-generation students come into the ADS course with less prerequisite course proficiency than their majority counterparts when analyzing differences in the pre-term test.

- Transfer and BLNPI students come in with less prerequisite course proficiency. We find the biggest gap in prerequisite course proficiency by transfer status with a statistically significant difference in pre-term test scores. Although there is not a statistically significant difference by BLNPI status, a substantial difference is seen that is similar to the difference for transfer status. The lack of significance may be due to the small sample size of BLNPI students.

- Consistent with the pre-term test results, Transfer and BLNPI students perform significantly worse than their majority counterparts in courses leading into the ADS course. BLNPI students perform significantly worse in all of the prerequisite courses of the ADS course compared to Non-BLNPI students. Transfer students perform significantly worse than non-transfer students in the two immediate predecessors of the the ADS course: Advanced Discrete Math and Computer Organization.

- Prerequisite course proficiency is correlated with student outcomes. We find prerequisite course proficiency (the pre-term test) to be statistically significantly correlated with both the ADS final exam score and ADS course grade for all populations except BLNPI students (which may be due to the small sample size).

- Transfer students' prerequisite course proficiency is not correlated with the number of prerequisites they take at our institution with the ADS course. There was not a statistically significant correlation between the number of courses taken at our institution and the pre-term test score.

These results show a disparity in who has prerequisite course proficiency, with BLNPI and transfer students having disproportionately lower pre-term test scores and prerequisite course grades. Further, these results suggest that institutions are not currently meeting the needs of these students. More work needs to be done to identify how we can best serve these populations.

\section{PREVIOUS WORK}

With regard to prerequisites, outside of CS, the relationship between prerequisite courses and student performance has been studied in Agriculture [17, 28], Business [11, 23], Physics [6] and many other fields [7, 24, 32]. Most studies have found that taking prerequisite courses is positively correlated with student success in the subsequent course [1, 7, 25].

In CS, prerequisite course chains are generally created so that an instructor can ensure students meet a certain baseline of knowledge before enrolling in their course [29]. This allows the instructor to build on top of this prerequisite course proficiency in order to teach more advanced concepts. The ACM curricula recommendations for CS from 2013 lists suggestions for such prerequisites [12].
With regards to demographic disparities, poor prerequisite course proficiency in CS may be tied to student experiences before entering university. Specifically, studies have shown the importance of prior programming experience before entering university $[9,10$, $30,31,33]$. Additionally, it has been found that students who did not complete any formal coursework before joining the computing major leave the major at a much higher rate [4]. Women, BLNPI students, and students that come from lower economic backgrounds often do not have access to prior computing experiences before entering university as majority populations $[15,16,30]$.

In 2019, a study by our research group showed that students in an Advanced Data Structures class were arriving with widely varying levels of proficiency with prerequisite subject matter [26]. About a third of the class arrived with a level of prerequisite course proficiency that was substantially below the expected level. A positive correlation between prerequisite course proficiency and success on the final exam was identified, indicating that students who are lagging behind in prerequisite course proficiency may continue to incur more gaps in their knowledge going forward in the CS program. A later study by our research group revealed a statistically significant correlation between students' prerequisite course grades and their prerequisite course proficiency and course outcomes [14].

In 2021, Valstar et al. used the validated Basic Data Structures Inventory [19] to test students' knowledge of basic data structures at different points throughout their degree to better understand how well students retain knowledge they learn earlier in their computing degree, whether it improves over time, and how it varies by demographic [27]. The results showed that student performance varied widely, but that performance on the basic data structures concepts seemed to improve as students move through the computing curriculum. In terms of demographics, the results showed that there is no difference by gender but that BLNPI students did slightly worse than their counterparts. The most concerning results were for transfer students, where there seems to be a growing gap in knowledge over time compared with non-transfer students.

Given the above results, we conjectured that groups that are traditionally underrepresented in computing may be disproportionately affected by worse outcomes in CS courses due to lower prerequisite proficiency. To shed light on this, we reanalyzed the data from our previous studies $[14,26]$ in view of demographic data we acquired from our institution.

\section{STUDY DESIGN}

\subsection{Research Questions}

RQ1: Does incoming prerequisite course proficiency to the ADS course vary by gender, BLNPI, first-generation and transfer student status?

RQ2: Is there a consistent gap in performance in the prerequisite courses to the ADS course by gender, BLNPI, firstgeneration and transfer student status?

RQ3: Is prerequisite course proficiency correlated with student outcomes in the ADS course and is there a difference in student outcomes by gender, BLNPI, first-generation and transfer student status?

RQ4: Do students who take more of their prerequisites at our institution, the same institution as the ADS course, have higher prerequisite course proficiency? 
Table 1: Number of participants (N) and percentage of Women; Black/Latinx/Native American/Pacific Islander (BLNPI); Transfer; First-generation (FG) students.

\begin{tabular}{|r|r|r|r|r|r|}
\hline Demographic & $N$ & Women & BLNPI & Transfer & FG \\
\hline Women & 102 & - & $5.9 \%$ & $17.7 \%$ & $17.7 \%$ \\
Men & 218 & - & $6.9 \%$ & $31.2 \%$ & $20.6 \%$ \\
\hline BLNPI & 21 & $28.6 \%$ & - & $14.3 \%$ & $47.6 \%$ \\
Non-BLNPI & 299 & $32.1 \%$ & - & $27.8 \%$ & $17.7 \%$ \\
\hline Transfer & 86 & $20.9 \%$ & $3.5 \%$ & - & $30.2 \%$ \\
Non-Transfer & 230 & $36.1 \%$ & $7.8 \%$ & - & $16.1 \%$ \\
\hline FG & 63 & $28.6 \%$ & $15.9 \%$ & $41.3 \%$ & - \\
Non-FG & 257 & $32.7 \%$ & $4.3 \%$ & $23.4 \%$ & - \\
\hline
\end{tabular}

\subsection{Course Context}

The ADS course is the first upper-division course taught at our computer science department at UC San Diego. The course teaches students about data structures (i.e., graphs, hash tables, breadth first search) and algorithms with projects in $\mathrm{C}++$. The course has five main prerequisites including introduction to programming (CS1), Data Structures (CS2), Discrete Math, Advanced Discrete Math and Computer Organization. There are alternative courses offered in other departments that can satisfy these prerequisites, though computer science majors are required to take the courses offered in the CS department. The primary chain of prerequisites can be seen in Figure 1.

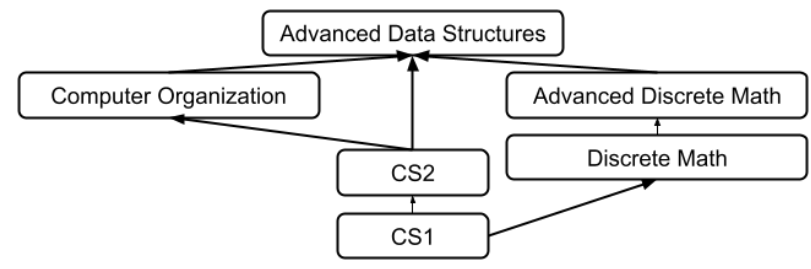

Figure 1: The primary prerequisite chain for the ADS course.

\subsection{Population}

Our population of students comes from the same course offering of the ADS course previously studied by our research group [14, 26]. For the purposes of our research, we could include all students who took the pre-term test that measured students' prerequisite course proficiency, which gave us 320 students. (See [26] for more details on the pre-term test).

We chose to look at the demographics of gender, BLNPI, transfer, and first-generation status. The demographic breakdowns can be seen in Table $1 .^{3}$

\subsection{Data Collection and Cleaning}

Our study expands on the pre-term test data, final exam scores, overall course grades, and prerequisite course grades collected by our research group $[14,26]$.

At our university, a 4.0 scale is used for course grades where a 4.0 represents an A and a 0.0 represents an F. Looking at the structure

\footnotetext{
${ }^{3}$ In the case of transfer and non-transfer students the number of participants do not add up to 320 due to four students not being included because they were neither freshman admits nor transfer students(e.g., exchange students or professionals attending a single class).
}

of our courses, a student who receives a grade of an $\mathrm{F}$ in a course $(0.0 / 4.0)$ usually receives closer to a $50 \%$ than a $0 \%$ in terms of their actual course grade. ${ }^{4}$ To account for this, we re-scaled course grades such that a 0.0 on the 4.0 scale is equivalent to 50 points on the 100 point scale. This was done for both the ADS course grade and all prerequisite course grades.

Additionally, all data used in this study was normalized using z-scores. Normalizing this data was important, as not all course offerings and courses are equal in terms of difficulty (an A in one course may not be equivalent to an $\mathrm{A}$ in another course). In the case of the prerequisite course grades, we used the $\mathrm{z}$-scores obtained from our previous work where we scraped our universities' online evaluation system for the course grade distributions for the relevant courses (for more details see [14]).

Finally, under our approved human-subjects protocol, we were able to obtain demographic information including gender, race/ethnicity, first-generation college status and whether students transferred from another college or university. For demographic information, we were only provided with a binary measure for whether students identified as Black, Latinx, Native American or Pacific Islander (BLNPI) versus students who identified as White or Asian (Non-BLNPI) to avoid accidentally deanonymizing students. For the case of gender, we were provided with a binary measure of whether students identified as women or men due to our university only collecting a binary Male/Female Category.

\section{RESULTS}

Using normality tests, we found that the data was not normally distributed and therefore we applied non-parametric tests for our analysis. This includes using Mann-Whitney U tests instead of independent sample t-tests, Spearman correlations instead of Pearson correlations, and Kruskal-Wallis H-Tests instead of ANOVAs. Due to the large number of statistical tests run during our analysis, we adjust our p-values to account for the increased chance of Type I errors. We used the Holm-Bonferroni adjustment method, as it reduces the probability of introducing Type II errors while not excessively diluting statistical power [2].

\subsection{RQ1: Incoming Prerequisite Course Proficiency by Demographic}

In order to understand whether there is a difference in students' incoming prerequisite course proficiency by demographic pair, we looked at the differences in students' scores on the pre-term test. The differences in mean and median pre-term test scores broken down by demographics as a percentage can be seen in Table 2 .

To determine whether there was a statistically significant difference between demographic pairs, we ran a Holm-Bonferroniadjusted Mann-Whitney U test for each pair (see Table 2). The only significant difference was for transfer status where transfer students did statistically significantly worse than non-transfer students. However, we do see a similarly large difference in pre-term test scores for BLNPI students. It may be that the lack of statistical significance is due to the small sample size $(N=21)$.

\footnotetext{
${ }^{4}$ This could be due to the fact that most students who are performing especially poorly at the beginning of the course drop it in order to avoid failing the course. Also, as discussed in Section 5, grades at our institution are generally high.
} 
Table 2: Performance details on the pre-term test by demographic. + and - for the mean and median diff indicate whether women, BLNPI, FG, and transfer students performed better or worse than their majority counterparts. A star $\left({ }^{*}\right)$ indicates a significant correlation for $\alpha=0.05$ according to a Holm-Bonferroni-adjusted Mann-Whitney $U$ test.

\begin{tabular}{|c|c|c|c|c|c|c|c|c|c|}
\hline Demographic & Group & $N$ & Mean & Mean Diff & Median & Median Diff & std dev & $\mathbf{U}$ & $\mathbf{p}$ \\
\hline \multirow{2}{*}{ Gender } & Women & 102 & $56.3 \%$ & \multirow{2}{*}{$-0.8 \%$} & $60.0 \%$ & \multirow{2}{*}{$+6.7 \%$} & $18.9 \%$ & \multirow{2}{*}{10983.5} & \multirow{2}{*}{0.86} \\
\hline & Men & 218 & $57.1 \%$ & & $53.3 \%$ & & $18.7 \%$ & & \\
\hline \multirow{2}{*}{ BLNPI Status } & BLNPI & 21 & $52.1 \%$ & \multirow{2}{*}{$-5.1 \%$} & $53.3 \%$ & \multirow{2}{*}{$-6.7 \%$} & $15.7 \%$ & \multirow{2}{*}{2622.0} & \multirow{2}{*}{0.31} \\
\hline & Non-BLNPI & 299 & $57.2 \%$ & & $60.0 \%$ & & $18.9 \%$ & & \\
\hline \multirow{2}{*}{ Transfer Status } & Transfer & 86 & $51.2 \%$ & \multirow{2}{*}{$-7.6 \%$} & $53.3 \%$ & \multirow{2}{*}{$-6.7 \%$} & $19.4 \%$ & \multirow{2}{*}{7816.0} & \multirow{2}{*}{$<0.01^{*}$} \\
\hline & Non-Transfer & 230 & $58.8 \%$ & & $60.0 \%$ & & $18.0 \%$ & & \\
\hline \multirow{2}{*}{ FG Status } & FG & 63 & $57.4 \%$ & \multirow{2}{*}{$+0.7 \%$} & $60.0 \%$ & \multirow{2}{*}{$0.0 \%$} & $20.1 \%$ & \multirow{2}{*}{8248.5} & \multirow{2}{*}{0.86} \\
\hline & Non-FG & 257 & $56.7 \%$ & & $60.0 \%$ & & $18.4 \%$ & & \\
\hline
\end{tabular}

Table 3: Holm-Bonferroni-adjusted Mann-Whitney $U$ test for differences in prerequisite course grades based on transfer and BLNPI status broken down by prerequisite course. A star $\left(^{*}\right)$ indicates a significant correlation for $\alpha=0.05$.

\begin{tabular}{|c|c|c|c|c|c|c|c|c|c|c|}
\hline \multirow[b]{3}{*}{ Course } & \multicolumn{5}{|c|}{ Transfer Status } & \multicolumn{5}{|c|}{ BLNPI Status } \\
\hline & \multicolumn{3}{|c|}{$\begin{array}{l}\text { Transfer/Non-Transfer } \\
\quad \text { Course Grade (z-score) }\end{array}$} & \multirow[b]{2}{*}{$\mathbf{U}$} & \multirow[b]{2}{*}{ p } & \multicolumn{3}{|c|}{ BLN/Non-BLN } & \multirow[b]{2}{*}{$\mathbf{U}$} & \multirow[b]{2}{*}{ p } \\
\hline & $N$ & mean & median & & & $N$ & mean & median & & \\
\hline CS1 & $31 / 229$ & $0.27 / 0.34$ & $0.41 / 0.56$ & 3156.0 & 0.43 & $18 / 242$ & $0.06 / 0.35$ & $0.04 / 0.56$ & 1557.0 & $0.04^{*}$ \\
\hline $\mathrm{CS} 2$ & $55 / 230$ & $0.30 / 0.29$ & $0.55 / 0.33$ & 6459.5 & 0.60 & $19 / 266$ & $0.01 / 0.31$ & $0.08 / 0.46$ & 1635.5 & $0.02^{*}$ \\
\hline Discrete Math & $51 / 207$ & $0.02 / 0.16$ & $0.07 / 0.14$ & 4773.0 & 0.43 & $20 / 240$ & $-0.31 / 0.17$ & $-0.32 / 0.19$ & 1621.0 & $<0.01^{*}$ \\
\hline Adv. Discrete Math & $85 / 225$ & $-0.11 / 0.19$ & $0.07 / 0.43$ & 7384.5 & $<0.01^{*}$ & $19 / 295$ & $-0.67 / 0.16$ & $-0.56 / 0.25$ & 1285.0 & $<0.01$ * \\
\hline Comp Org & $59 / 202$ & $-0.16 / 0.20$ & $-0.05 / 0.39$ & 4257.5 & $<0.01^{*}$ & $17 / 247$ & $-0.13 / 0.14$ & $-0.01 / 0.28$ & 1574.5 & $0.04^{*}$ \\
\hline
\end{tabular}

\subsection{RQ2: Comparing Demographic Pairs' Prerequisite Grades}

Our previous work on this data showed that the pre-term test is correlated with prerequisite course grades [14]. This led us to the question of whether we would find similar results to RQ1 when looking at students' prerequisite course grades instead of pre-term test scores. We expect the pre-term test to be an accurate measure of students' prerequisite course proficiency because it is given at the beginning of the quarter and is specifically focused on prerequisite course content, although it is a short instrument that only takes 20 minutes to complete. Prerequisite course grades each represent 10 weeks of knowledge and may capture nuances that the pre-term test does not.

To measure this we ran Holm-Bonferroni-adjusted MannWhitney U tests comparing each demographic pairs' course grades for each of the five prerequisite courses of the ADS course (CS1, CS2, Discrete Math, Advanced Discrete Math and Computer Organization). Table 3 shows the results of these tests, as well as, the mean and median course grades as z-scores (e.g., in the Computer Organization course, transfer students were 0.16 standard deviations below the mean course grade and non-transfer students were 0.20 standard deviations above). Due to students' ability to use AP credit towards course requirements, take summer school and transfer credits during their time at our university, the number of students does not always add up to the the same number in these comparisons.

Similarly to the results of RQ1, we see no statistically significant differences for gender. For first-generation students, we only see a statistically significant difference in the Advanced Discrete Math course $(U=5928, \alpha=0.01)$. For BLNPI students, we see a statistically significant difference in all of the prerequisite course grades with BLNPI students performing worse. We find that transfer students perform statistically significantly worse than non-transfer students in Advanced Discrete Math and Computer Organization. This suggests that the gap in knowledge for BLNPI and transfer status begins earlier in the program, manifests itself as poor prerequisite course proficiency, and that poor prerequisite course proficiency correlates with student outcomes in later courses.

\subsection{RQ3: Prerequisite Course Proficiency's Impact on Student Outcomes}

Our prior work on this data set has shown that prerequisite course proficiency is correlated with student success [26] and that students' incoming prerequisite course proficiency is correlated with their performance in the course, including their ADS course grades and final exam scores [14]. We wanted to see if (1) prerequisite course proficiency was still correlated with student outcomes when looking at the different demographic groups and (2) if there were differences in student outcomes between demographic pairs.

First, we used Spearman correlations with Holm-Bonferroniadjusted p-values to examine the relationship between each demographics' pre-term test scores and their ADS course grades, and final exam scores (see Table 4). For all groups except for BLNPI students ${ }^{5}$ we found prerequisite course proficiency to be statistically significantly correlated with students' ADS course outcomes.

After seeing that all demographics have a strong and statistically significant correlation between prerequisite course proficiency and

\footnotetext{
${ }^{5}$ The lack of statistical significance for BLNPI students may be due to the small sample.
} 
course outcomes (aside from BLNPI students), we wanted to know if there is a statistically significant difference between demographics pairs' ADS course outcomes. To do this, we ran a Holm-Bonferroniadjusted Mann-Whitney U test comparing each demographic pairs' course grades and final exam scores (see Table 5).

Here we find no statistically significant difference in course outcomes by gender, first-generation, or BLNPI status. We do find a statistically significant difference for the ADS final exam scores by transfer status, with transfer students performing worse. The results for BLNPI students are not statistically significant, but the mean and median differences in the final exam score are similar to that of transfer and non-transfer students leading us to believe this may be due to the small sample size of BLNPI students.

\subsection{RQ4: Comparing Prerequisite Course Proficiency by Number of Prerequisites Taken at Our University}

Transfer students enter our institution with different numbers of prerequisite courses for ADS already completed. Given their average lower performance on the pre-term test, we next ask whether taking more of the prerequisite courses at our institution could result in better performance, perhaps because of better alignment of learning outcomes. To measure this, we grouped the transfer students based on how many prerequisites they took at our university (no transfer students took all of their prerequisites at another university). We then ran a Kruskal-Wallis H-Test, which is a nonparametric equivalent of an ANOVA, to determine whether there was a difference between transfer students' pre-term test scores based on how many courses they took at our university, ranging from one to five courses. The results were statistically significant with the statistic of stat $=10.19$ and a p-value of $\alpha=0.04$. To determine which groups of transfer students differed, we then performed a Post-Hoc Dunn's test using a Bonferroni correction to correct for running multiple statistical tests. The results showed that there was no statistically significant difference between transfer students no matter how many prerequisites they took at our university.

These results suggests that the number of prerequisites a transfer student takes at our university may not impact their prerequisite course proficiency. The reason we see a global difference but not a difference in the Post-Hoc Dunn's is due to correcting for running multiple statistical tests. It may be that with larger number of participants we would see a statistically significant difference between groups and be able to identify where these differences are.

\section{DISCUSSION}

These results suggest that we may need to look for other factors that are leading to disparities in student outcomes for women and first-generation students. We caution that prerequisite course proficiency may still be an issue for these groups, as it's possible that the women and first-generation students who might have struggled have already self-selected out of computing before they reach the ADS course.

5.0.1 BLNPI students. It appears that prerequisite course proficiency may be playing a role in the outcome disparities between BLNPI and Non-BLNPI students. We see that there is a gap between BLNPI and Non-BLNPI students' grades in all of their prerequisite
Table 4: Spearman correlations with Holm-Bonferroniadjusted p-values between performance on pre-term test and ADS final exam score and course grade. A star ( $\left.{ }^{*}\right)$ indicates a significant correlation for $\alpha=0.05$.

\begin{tabular}{|c|c|c|c|c|}
\hline \multirow[b]{2}{*}{ Group } & \multicolumn{2}{|c|}{ ADS Final Exam } & \multicolumn{2}{|c|}{ ADS Grade } \\
\hline & $\mathbf{r}$ & $\mathbf{p}$ & $\mathbf{r}$ & $\mathbf{p}$ \\
\hline Women & 0.47 & $<0.01 *$ & 0.47 & $<0.01 *$ \\
\hline Men & 0.31 & $<0.01^{*}$ & 0.26 & $<0.01^{*}$ \\
\hline BLNPI & 0.16 & 0.48 & 0.33 & 0.14 \\
\hline Non-BLNPI & 0.37 & $<0.01^{*}$ & 0.33 & $<0.01$ * \\
\hline Transfer & 0.42 & $<0.01^{*}$ & 0.40 & $<0.01 *$ \\
\hline Non-Transfer & 0.32 & $<0.01^{*}$ & 0.29 & $<0.01^{*}$ \\
\hline $\mathrm{FG}$ & 0.43 & $<0.01 *$ & 0.38 & $<0.011^{*}$ \\
\hline Non-FG & 0.34 & $<0.01^{*}$ & 0.32 & $<0.01^{*}$ \\
\hline
\end{tabular}

courses leading into the ADS course, as well as in their pre-term test scores. Work by Alvarado et al. found statistically significant differences in course grades throughout students' undergraduate computing careers based on whether students had computing experiences prior to entering university [3]. This suggests that the gap we see for BLNPI status in the prerequisite course grades and preterm test may be due to lacking prior experiences before entering university. This may also be true for transfer students, though we only see a statistically significant gap in prerequisite course grades for the two immediate predecessors of the ADS course.

5.0.2 Transfer students. For transfer students, we see the most sizable results in terms of differences in pre-term test scores and ADS final exam scores. We also find that pre-term test scores are correlated with outcomes in the ADS course. Interestingly, we do not find strong evidence to suggest the gap by transfer status is related to the number of courses transfer students take at our university. This suggests a solution to the problem is not as simple as requiring transfer students to take all of their ADS prerequisites at our university. However, we caution that due to the small sample size of transfer students in each group, we may have seen statistically significant differences between groups if we had a larger population.

5.0.3 Differences in ADS course grades \& final exam scores. When we look at the ADS course grades we find that they are very similar for the entire population of students seen in Table 5. This is likely due to the grading scheme of this course, which is representative of the typical grading scheme at our university, where a large proportion of the course grade rewards effort or may indirectly allow students to collaborate ${ }^{6}$ (often $50 \%$ of the course grade). Unfortunately, grades that are inflated by effort and collaboration allow students and institutions to ignore students' lack of proficiency of course material in the short term, while leading to long-term issues. The average and median grades for the ADS course are $93.5 \%$ and $96 \%$. It is extremely unlikely the majority of the students in the course have proficiency of the material at the level equivalent to receiving an $\mathrm{A}$ in the course.

\footnotetext{
${ }^{6}$ The ADS course grade breakdown is online reading assignments (10\%), clicker participation (5\%), programming assignments (35\%), midterm (20\%), in-class quizzes (5\%), and final exam $(25 \%)$
} 
Table 5: Performance details on the ADS final exam and ADS course grade by demographic. A star $\left({ }^{*}\right)$ indicates a significant correlation for $\alpha=0.05$ according to a Holm-Bonferroni-adjusted Mann-Whitney $U$ test.

\begin{tabular}{|c|c|c|c|c|c|c|c|c|c|c|c|c|}
\hline \multirow[b]{2}{*}{ Demographic } & \multirow[b]{2}{*}{ Group } & \multirow[b]{2}{*}{$N$} & \multicolumn{5}{|c|}{ ADS Final Exam } & \multicolumn{5}{|c|}{ ADS Grade } \\
\hline & & & Mean & Median & std dev & $\mathbf{U}$ & $\mathbf{p}$ & Mean & Median & std dev & $\mathbf{U}$ & $\mathbf{p}$ \\
\hline \multirow{2}{*}{ Gender } & Women & 102 & $81.2 \%$ & $83.3 \%$ & $10.2 \%$ & \multirow{2}{*}{10780.0} & \multirow{2}{*}{0.44} & $93.1 \%$ & $96.0 \%$ & $10.2 \%$ & \multirow{2}{*}{11164.5} & \multirow{2}{*}{0.53} \\
\hline & Men & 218 & $81.8 \%$ & $84.0 \%$ & $9.4 \%$ & & & $93.6 \%$ & $96.0 \%$ & $8.8 \%$ & & \\
\hline \multirow{2}{*}{ BLNPI Status } & BLNPI & 21 & $78.8 \%$ & $80.7 \%$ & $10.8 \%$ & \multirow{2}{*}{2618.0} & \multirow{2}{*}{0.31} & $92.5 \%$ & $96.0 \%$ & $7.3 \%$ & \multirow{2}{*}{2595.5} & \multirow{2}{*}{0.28} \\
\hline & Non-BLNPI & 299 & $81.8 \%$ & $84.0 \%$ & $9.5 \%$ & & & $93.5 \%$ & $96.0 \%$ & $9.4 \%$ & & \\
\hline \multirow{2}{*}{ Transfer Status } & Transfer & 86 & $79.3 \%$ & $81.0 \%$ & $10.1 \%$ & \multirow{2}{*}{8079.0} & \multirow{2}{*}{$0.02^{*}$} & $92.5 \%$ & $96.0 \%$ & $9.6 \%$ & \multirow{2}{*}{8886.5} & \multirow{2}{*}{0.28} \\
\hline & Non-Transfer & 230 & $82.4 \%$ & $84.0 \%$ & $9.4 \%$ & & & $93.8 \%$ & $96.0 \%$ & $9.2 \%$ & & \\
\hline \multirow{2}{*}{ FG Status } & FG & 63 & $81.0 \%$ & $81.3 \%$ & $10.0 \%$ & \multirow{2}{*}{7589.5} & \multirow{2}{*}{0.44} & $92.7 \%$ & $96.0 \%$ & $10.3 \%$ & \multirow{2}{*}{7563.0} & \multirow{2}{*}{0.39} \\
\hline & Non-FG & 257 & $81.8 \%$ & $84.0 \%$ & $9.5 \%$ & & & $93.7 \%$ & $96.0 \%$ & $9.0 \%$ & & \\
\hline
\end{tabular}

This suggests something needs to be changed in how we run our courses and how we grade our students. We need to provide students with a more accurate measure of their understanding of course material. Merely passing a course is not enough to determine course proficiency and, as we see in the ADS course grades, even passing the course with a high mark is not always representative of having proficiency in the course material.

5.0.4 Mastery learning. One idea to fix this problem is mastery learning [5]. In mastery learning, learning goals are organized into well-defined units and students must master a unit before proceeding to the next one. Mastery learning cannot be directly implemented in universities for many reasons including increasing students' time to degree, but concepts from mastery learning can be applied to how we structure our courses. We can test our students on concepts more regularly so they are able to gauge their understanding, and if a student does not perform well, we can give them resources to study and allow them to be retested until they understand the concepts. Some researchers in CS education have already begun to look into this, as seen in the literature review conducted by Garner et al. [8] and more recently by Ott et al. [18]. Lack of past prerequisite course proficiency is statistically significantly correlated with lack of future course proficiency, and this issue falls disproportionately on BLNPI and transfer students. Not requiring a higher level of proficiency in course material before allowing students to move on to the next course is doing a disservice to the students in populations that are disproportionately affected.

5.0.5 Intersectionality between demographic groups. Finally, more work needs to be done to understand the possible effects of intersectionality. It is unlikely our results for BLNPI and transfer students are strongly influenced by cross-membership in these groups, as each is represented in the other in small percentages (Table 1). However, there could be intersectionality effects for individual students, even with groups that did not show lower prerequisite course proficiency. The small sample sizes of the populations we examined in this paper necessitated leaving this analysis for future work.

\subsection{Limitations and Threats to Validity}

The results of this study are limited in that they come from a single course offering of an Advanced Data Structures course at a research intensive university. However, our university curriculum does follow the ACM Curriculum Guidelines [12], which leads us to believe that the findings from this study may be similar to other institutions following the same guidelines.

Additionally, the pre-term test is not a validated instrument, which could lead to an incorrect estimation in students' prerequisite course proficiency. Students were also not provided with an incentive to complete the pre-term test and therefore may not have had the proper motivation to try and perform well. The pre-term test was also given in class and therefore students who did not show up were not included in the study, which may impact the results.

In terms of demographics, we had a small number of students for many of the populations we studied. This may have impacted our results in terms of statistical significance.

\section{CONCLUSION}

Prior work has shown that prerequisite course proficiency matters $[14,26]$. Our work extends our understanding of the importance of prerequisite course proficiency by showing that it varies by demographic groups and how it relates to disparities in student outcomes. Interestingly, we did not see a substantial or statistically significant difference in prerequisite course proficiency for gender or first-generation status. However, we did find substantial disparities for BLNPI and transfer students. This is statistically significant for transfer students, but not BLNPI students, likely due to their small numbers in our study. We find that prerequisite course proficiency is correlated with students' ADS course grades and final exam scores, and we find that transfer students do significantly worse on the ADS final exam than non-transfer students. We see similarly substantial, but non-significant, results for BLNPI students. When looking at students' prerequisite course grades, we find that BLNPI and transfer students perform statistically significantly worse than their majority counterparts. This suggests that the gap between BLNPI and Non-BLNPI and transfer and non-transfer students' knowledge begins earlier in the program, manifests itself as poor prerequisite course proficiency, and that poor prerequisite course proficiency correlates with their outcomes in later courses. Overall our study shows a disparity in prerequisite course proficiency between demographic groups, specifically for BLNPI and transfer students who are experiencing the worst effects.

Institutions need to find ways to support these students. Our findings necessitate more studies focused on better understanding the role prerequisite preparation may have on the outcomes of traditionally underrepresented groups in computing. 


\section{ACKNOWLEDGMENTS}

This material is based upon work supported by the National Science Foundation Graduate Research Fellowship Program under Grant No. DGE-1650112, NSF Award \#2121592, NSF Award \#1712508 as well as a program assessment grant from the office of UC San Diego's Dean of Undergraduate Education.

\section{REFERENCES}

[1] Tope Adeyemi-Bello, Amy McMillan, and Amy McMillan-Capehart. 2011. Prerequisite Coursework As A Predictor Of Performance In A Graduate Management Course. Fournal of College Teaching and Learning 5 (2011).

[2] Mikel Aickin and Helen Gensler. 1996. Adjusting for multiple testing when reporting research results: the Bonferroni vs Holm methods. American fournal of Public Health 86, 5 (1996), 726-728.

[3] Christine Alvarado, Gustavo Umbelino, and Mia Minnes. 2018. The Persistent Effect of Pre-College Computing Experience on College CS Course Grades. In Proceedings of the 49th ACM Technical Symposium on Computer Science Education (SIGCSE '18). 876-881.

[4] Maureen Biggers, Anne Brauer, and Tuba Yilmaz. 2008. Student Perceptions of Computer Science: A Retention Study Comparing Graduating Seniors with Cs Leavers. In Proceedings of the 39th SIGCSE Technical Symposium on Computer Science Education (SIGCSE '08). 402-406.

[5] James H. Block. 1971. Mastery learning: Theory and practice. Holt, Rinehard and Winston, Inc.

[6] Eric W. Burkholder, Gabriel Murillo-Gonzalez, and Carl Wieman. 2021. Importance of math prerequisites for performance in introductory physics. Physical Review Physics Education Research 17 (2021), 010108-1-010108-14. Issue 1.

[7] Joseph P. Forester, David L. McWhorter, and Maria S. Cole. 2002. The relationship between premedical coursework in gross anatomy and histology and medical school performance in gross anatomy and histology. Clinical Anatomy: The Official Journal of the American Association of Clinical Anatomists and the British Association of Clinical Anatomists 15, 2 (2002), 160-164.

[8] James Garner, Paul Denny, and Andrew Luxton-Reilly. 2019. Mastery Learning in Computer Science Education. 37-46.

[9] Dianne Hagan and Selby Markham. 2000. Does it help to have some programming experience before beginning a computing degree program?. In Proceedings of the 5th Annual Conference on Innovation and Technology in Computer Science Education (ITiCSE' '00). 25-28.

[10] Edward Holden and Elissa Weeden. 2003. The impact of prior experience in an information technology programming course sequence. In Proceedings of the 4th conference on Information technology curriculum (CITC4 '03). 41-46.

[11] Faridul Islam, Saleheen Khan, Ian Wilson, and Reed Gooch. 2008. The Value of Prerequisite Courses for Statistics. The fournal of Business Inquiry 7, 1 (2008), 61-67.

[12] Association for Computing Machinery (ACM) Joint Task Force on Computing Curricula and IEEE Computer Society. 2013. Computer Science Curricula 2013 Curriculum Guidelines for Undergraduate Degree Programs in Computer Science.

[13] Sophia Krause-Levy, William G. Griswold, Leo Porter, and Christine Alvarado. 2021. The Relationship Between Sense of Belonging and Student Outcomes in CS1 and Beyond. In Proceedings of the 17th ACM Conference on International Computing Education Research. 29-41.

[14] Sophia Krause-Levy, Sander Valstar, Leo Porter, and William G. Griswold. 2020 Exploring the Link Between Prerequisites and Performance in Advanced Data Structures. In Proceedings of the 51st ACM Technical Symposium on Computer Science Education (SIGCSE '20). 386-392.

[15] Jane Margolis, Rachel Estrella, Joanna Goode, Jennifer Jellison Holme, and Kim Nao. 2010. Stuck in the shallow end: Education, race, and computing. MIT Press.
[16] Jane Margolis and Allan Fisher. 2003. Unlocking the clubhouse: Women in computing. MIT press.

[17] Marshall A. Martin. 1989. Course prerequisites and undergraduate student performance. NACTA fournal 33, 1 (1989), 38-42.

[18] Claudia Ott, Brendan McCane, and Nick Meek. 2021. Mastery Learning in CS1 An Invitation to Procrastinate?: Reflecting on Six Years of Mastery Learning. In Proceedings of the 26th ACM Conference on Innovation and Technology in Computer Science Education (ITiCSE '21). 18-24.

[19] Leo Porter, Daniel Zingaro, Soohyun Nam Liao, Cynthia Taylor, Kevin C. Webb, Cynthia Lee, and Michael Clancy. 2019. BDSI: A Validated Concept Inventory for Basic Data Structures. In Proceedings of the 2019 ACM Conference on International Computing Education Research (ICER '19). 111-119.

[20] Adam Rosenstein, Aishma Raghu, and Leo Porter. 2020. Identifying the prevalence of the impostor phenomenon among computer science students. In Proceedings of the 51st ACM Technical Symposium on Computer Science Education (SIGCSE '20). 30-36.

[21] Adrian Salguero, William G. Griswold, Christine Alvarado, and Leo Porter. 2021. Understanding Sources of Student Struggle in Early Computer Science Courses. 319-333.

[22] Adrian Salguero, Julian McAuley, Beth Simon, and Leo Porter. 2020. A Longitudinal Evaluation of a Best Practices CS1. In Proceedings of the 2020 ACM Conference on International Computing Education Research (ICER '20). 182-193.

[23] Burton F. Schaffer and D. Ordell Calkins. 1980. An Appraisal of Prerequisites to Business Finance. Journal of Financial Education 9 (1980), 51-55.

[24] Justin F Shaffer, Jennifer V Dang, Amanda K Lee, Samantha J Dacanay, Usman Alam, Hollie Y Wong, George J Richards, Pavan Kadandale, and Brian K Sato. 2016. A familiar (ity) problem: Assessing the impact of prerequisites and content familiarity on student learning. PloS one 11, 1 (2016), e0148051.

[25] Krista M. Soria and Lori Mumpower. 2012. Critical building blocks: Mandatory prerequisite registration systems and student success. NACADA fournal 32, 1 (2012), 30-42.

[26] Sander Valstar, William G. Griswold, and Leo Porter. 2019. The Relationship Between Prerequisite Proficiency and Student Performance in an Upper-Division Computing Course. In Proceedings of the 50th Technical Symposium on Computer Science Education. 794-800.

[27] Sander Valstar, Sophia Krause-Levy, Adrian Salguero, Leo Porter, and William G. Griswold. 2021. Proficiency in Basic Data Structures among Various Subpopulations of Students at Different Stages in a CS Program (ITiCSE '21). 429-435.

[28] J.D. Vitale, S.P. Wanger, and D.C. Adams. 2010. Explaining student performance in an undergraduate agricultural economics classroom. NACTA fournal 54, 1 (2010), 2.

[29] Henry M. Walker. 2010. Prerequisites: Shaping the Computing Curriculum. ACM Inroads 1, 4 (2010), 14-16.

[30] Jennifer Wang, Hai Hong, Jason Ravitz, and Sepehr Hejazi Moghadam. 2016. Landscape of K-12 Computer Science Education in the U.S.: Perceptions, Access, and Barriers. In Proceedings of the 47th ACM Technical Symposium on Computing Science Education (SIGCSE '16). 645-650.

[31] Brenda Cantwell Wilson and Sharon Shrock. 2001. Contributing to success in an introductory computer science course: a study of twelve factors. ACM SIGCSE Bulletin 33, 1 (2001), 184-188.

[32] Robin Wright, Sehoya Cotner, and Amy Winkel. 2009. Minimal impact of organic chemistry prerequisite on student performance in introductory biochemistry. CBE-Life Sciences Education 8, 1 (2009), 44-54.

[33] Daniel Zingaro, Michelle Craig, Leo Porter, Brett A. Becker, Yingjun Cao, Phill Conrad, Diana Cukierman, Arto Hellas, Dastyni Loksa, and Neena Thota. 2018. Achievement Goals in CS1: Replication and Extension. In Proceedings of the 49th Technical Symposium on Computer Science Education (SIGCSE '18). 687-692.

[34] Stuart Zweben. 2019. Enrollment and Retention in U.S. Computer Science Bachelor's Programs in 2016-17. ACM Inroads 10, 4 (2019), 47-59.

[35] Stuart Zweben and Betsy Bizot. 2019. 2019 Taulbee Survey: Total Undergrad CS Enrollment Rises Again, but with Fewer New Majors; Doctoral Degree Production Recovers from Last Year's Dip. 2, 5 (2019). 